\title{
From Paradox to Fudgment: towards a metaphysics of expression
}

\author{
Mariam Thalos* \\ UNIVERSITY OF UTAH \\ mthalos@philosophy.utah.edu \\ Received by Greg Restall \\ Published October 6, 2005 \\ http://www.philosophy.unimelb.edu.au/aj1/2005 \\ (c) 2005 Mariam Thalos
}

\begin{abstract}
The Liar sentence is a singularly important piece of philosophical evidence. It is an instrument for investigating the metaphysics of expressing truths and falsehoods. And an instrument too for investigating the varieties of conflict that can give rise to paradox. It shall serve as perhaps the most important clue to the shape of human judgment, as well as to the nature of the dependence of judgment upon language use.
\end{abstract}

\section{A FALSE DOCTRINE ABOUT TRUTH}

Alfred Tarski was first to advance what he called the semantic account of truth. Truth, on this account, is a feature of sentences, meriting no special metaphysical story-indeed, it is purely a feature of sentences in an object language distinct from that in which the truth schema is expressed:

(T) $x$ is true if and only if $p$;

In this schema ' $x$ ' names a sentence which is translated into the metalanguage by 'p.'

${ }^{*}$ This essay has been nearly a decade in the making, having passed through versions by the dozens. It has benefited from the gaze of numerous kind colleagues as well as from the accumulated scrutinies of anonymous reviewers. I want to thank everyone-and they know better than I do who they are-who has thrown open their store of intellectual wisdom for this essay's sake, without blaming anyone but my stubborn self for such errors and infelicities as might still remain. But as much pleasure as it would give me to do so, I cannot name all who have contributed, even if I knew or could remember their names. Nonetheless special thanks are due to Laurence Goldstein, John Kearns, Lije Millgram, Graham Priest, Greg Restall, and (as nearly always) Barry Smith.

I"The concept of truth in formalized languages," tr. in A. Tarski, I983, Logic, Semantics, Metamathematics, second edition, ed. J. Corcoran, tr. J. Woodger (Indianapolis: Hackett). 
Although many since Tarski have done so, Tarski himself did not consider (T) to be a definition of truth, but instead a condition of adequacy in handling the predicate "true declarative sentence of L": any definition of truth must have all the instances of $(T)$ as a consequence. And many have taken $(T)$ to be a platitude, and indeed such as to say "nothing that would be disagreed with by a correspondence theorist, coherence theorist or deflationist.'2

Quibbles aside 3 there is a very simple and substantive argument establishing decisively that this account of truth is mistaken. It relies upon the fact that a certain sentence is expressible-namely the Liar sentence:

(L) Sentence (L) is not true.

Of course, Tarski and others exclude the Liar from the scope of the T-schema. Tarski does it by forbidding semantic closure, and so making (L) inexpressible. P. Horwich simply excludes paradoxical instances of $(T)$ from the infinite conjunction of its instance ${ }^{4}$

Any maneuver to exclude (L) is costly: if none of the languages we undertake to describe truth in, admit of formulation of $(\mathrm{L})$, how shall we learn the philosophical lessons that $(\mathrm{L})$ portends? And, in point of simple fact, $(\mathrm{L})$ is not excluded by natural language. We shall miss out on all the substantive philosophy that can be wrought upon contemplation of this truth itself. With similar sentiments, Stephen Yablo writes:

That the same rules [for semantic assessment of sentences or utterances] which cause so much trouble in certain of their applications yield unequivocal and intuitive results in all the others seems to show that the paradoxes can exist in, and indeed issue out of, a substantially healthy nature. This creates strong pressure for leaving things [vis-à-vis rules for semantic assessment] as they are, on pain of undermining the very principles which guide the enterprise. The treatment of choice might well be benign neglect:5

The question of whether (L) is a sign of semantic disease shall be of some concern here, and especially the question of what semantic disease consists in. First, however, we shall draw attention to the philosophical morals that (L) brings to attention. The first of these is that truth is not a purely semantic matter-a feature of sentences alone.

\footnotetext{
${ }^{2}$ Julian Dodd, "Is Truth Supervenient on Being?", Proceedings of the Aristotelian Society IO2 (200I-2), 69-86, p. 75 .

${ }^{3}$ I am referring here to the concerns expressed by D. Davidson, "True to the facts," four nal of Philosophy 66 (1969) 304-323; and J. Hintikka, "A counterexample to Tarski-type truthdefinitions as applied to natural languages," Philosophia 5 (I975) 207-2I2. I take these to be serious issues, but not as fundamental as those I shall present.

"Truth, second edition 1998, Oxford: Clarendon.

5"Truth and Reflection," Fournal of Philosophical Logic I4 (1985) 297-349, p. 302.
} 
THE SIMPLE ARGUMENT

And so consider the Liar sentence:

(L) Sentence (L) is not true.

This sentence is not eligible of truth, since assuming that it is leads to contradiction. So truth cannot be a feature of all declarative sentences. Some declarative sentences, perhaps, but certainly not all of them. This casts a shadow of doubt upon the notion that we can identify all the true sentences simply by identifying those in declarative mode.

\section{AN IMPORTANT GUIDING ANALOGY}

To place a call on my telephone, I lift the receiver, thereby signaling a need for service, and dial a phone number in service. But if I lift the receiver and dial my own number, I am greeted with a busy tone. I cannot make a connection with myself. With phone circuitry being organized as it is, I cannot make a call and speak into my own earpiece. This is a fact about the physics and metaphysics of phone circuitry. Clearly, it does not show that no-one else can phone and speak into my earpiece. Nor does it show that there is something terribly wrong with the way our circuitry is organized. Nor does it mean that we could alter our circuitry so as to allow me to make a connection with myself: it is possible that we might be able so to organize our circuitry, but it is also possible that we might not be so able. And what it might take to achieve this feat may be of such an order of magnitude of difference from current technology that it might be unrecognizable to us as telephonic circuitry.

Similarly, I cannot manage to make a statement-to say something —-through giving voice to (L). With the apparatus of language organized as it is, neither I-nor anyone else - can voice an opinion-something that can be evaluated as to truth or falsity - by means of $(\mathrm{L})$. This is a fact about the metaphysics of language and speechmaking. By no means does it establish that there is no other way of saying something in the neighborhood of (L) - I will argue below that something in the neighborhood can be said—indeed, it is the very point we are trying to make now, to the effect that no-one can use (L) to make a statement of any kind. And by no means does this fact establish that there is something wrong with the way our language is organized (as some approaches to the Liar intimate). Nor indeed can it show that we could organize our speechmaking so as to allow (L) something to say. (Perhaps to give Liar something to say would take a linguistic technology of which we are not capable.) In any case, these are unknowns that do not challenge our lofty ability to speechify. Nor do they challenge the notion of truth itself. But they do show that the achievement of truth, when it is achieved, depends on much more than linguistic form. It is a matter of the metaphysics of speechmaking. This shall be the theme of my essay. 
PROJECTING, BELIEVING AND AIMING

Dependable Alfred tells Brenda: "I will pay you a visit this weekend, at noontime, and will take you by surprise thereby." Subsequently Brenda reasons as follows:

Alfred cannot, in keeping with his promise, come calling on Sunday, because on Saturday evening I would know with absolute certainty that he shall be calling the following day. So he must be intending to call on Saturday. But how can he, knowing that I can so easily eliminate Sunday as a possible day for his visit, now that I knowand he knows I know-about his intentions, and so anticipate a Saturday visit, thereby preventing him fulfilling his promise? He must be intending a Sunday visit after all. Still, on Saturday evening I should know with absolute certainty that Saturday is eliminated, and so only Sunday remains for fulfilling the promise. So it cannot be Sunday after all. But ...

The conditions under which Brenda is seeking to formulate an anticipation as to what the future holds, through normal channels involving apparently unimpeachable rationales for eliminating possibilities, do not favor bringing her undertaking to a satisfactory conclusion. For no sooner is one day eliminated, than it returns to claim title to further consideration ${ }^{6}$

Is Alfred's announcement inconsistent with Brenda's knowledge of it? No. For if Brenda remains conscientiously suspended as we find her in the story, Alfred may visit on either day-but preferably on Saturday, as this would prevent Brenda reaching new levels of perplexity—and Brenda will be taken by surprise. Now Alfred could have kept Brenda in the dark about his intention to visit this weekend, and thus given her no basis for forming an anticipation as to the day of it. And in that way he could have achieved his aim of taking her by surprise. But he does not, and instead declares his intention to her himself, openly and deliberately, and achieves the desired effect thereby. This fact cries out for explanation.

Brenda, having been informed of Alfred's intention, must be prepared to take into account also the matter from Alfred's point of view, when reviewing her prospects. And if she would have it that her anticipations be well-founded, she must realize that Alfred's part must be supported by reasons that take also into account her potential reasonings. For she knows that Alfred will have to decide upon a day this weekend, such that he can project that when he comes calling, Brenda will not be expecting him. And she knows that he will have to do this with full knowledge of his having declared his intention to her, and

\footnotetext{
${ }^{6}$ Obviously, this is a version of the surprise execution or surprise examination paradox. My full treatment of this paradox is in "Conflict and Coordination in the Aftermath of Oracular Statements," Philosophical 2uarterly 47 (1997), 212-226.
} 
with full knowledge too that she, Brenda, also knows this. I will call projections those beliefs or anticipations which are produced at least partly on the basis of anticipations of other individuals' reasoning processes, and on the assumption that those other individuals are projecting beings too. The action of making a projection I will call projecting. And I will argue that Brenda's undertaking, which is inspired (or rather, provoked) by Alfred's announcement, cannot be consummated.

What can go wrong en route to a satisfactory conclusion of deliberations in circumstances such as Brenda's? The process of deliberations that she has undertaken is one that requires projections; in fact, it requires reciprocal projections. Reciprocal projections are normally self-reflective: the reflections themselves are among those matters on which those very projections rest. And this is where things are liable to go wrong, when conditions are unfavorable, as they are in Brenda's case. For her circumstances are such that the normal procedure for consummating projections will not halt. This fact comes out most transparently when the situation is looked at from Alfred's side of things. For the halting of deliberations is a precondition for a surprise visit (since Alfred has to make a selection first, and only subsequently bring it to reality in the warm world of action), yet the truth-bearer that deliberations have halted entails that no surprise visit can come about, since halting indicates that the day of the visit can be (since it has been) anticipated-at least by Alfred. And yet Alfred (at least according to his promise) has figured out how to resolve this small difficulty. He achieves the appearance of having accomplished this impossible task, simply by making a statement whose announcement presupposes this task's accomplishment.

The flowchart of Figure $\mathrm{I}$ is one way of formalizing the process of eliminations that neither Brenda nor Alfred can escape. The decision depicted within the dotted portion must be made at every cycle, and at every cycle the answer must be No; for one cannot be making a decision if one is halted. This diagrammatic representation of the procedure undertaken by Brenda, and which must be attributed to her also by Alfred, illuminates why a surprise visit can be achieved even if Alfred offers Brenda only one possible day for his visit ("I shall come calling tomorrow, and will take you by surprise thereby"). For the process does not depend at all on the number of possible days, so long as this number is not zero.

Now Brenda can know, as we do, that the procedure she is undertaking does not terminate. Does this help? In fact, no. This knowledge might lead her to believe, at least temporarily, that Alfred, prior to making his announcement, must have used some procedure-maybe this, maybe that-different from the one she is currently using to anticipate his intention, possibly even some randomizing mechanism such as a coin toss. So she prepares to resign herself to being surprised. On further reflection, however, she realizes that if he has used a randomizing device, then he must have eliminated Sunday as a potential day to be selected by lottery, since (as he can anticipate Brenda will come to real- 


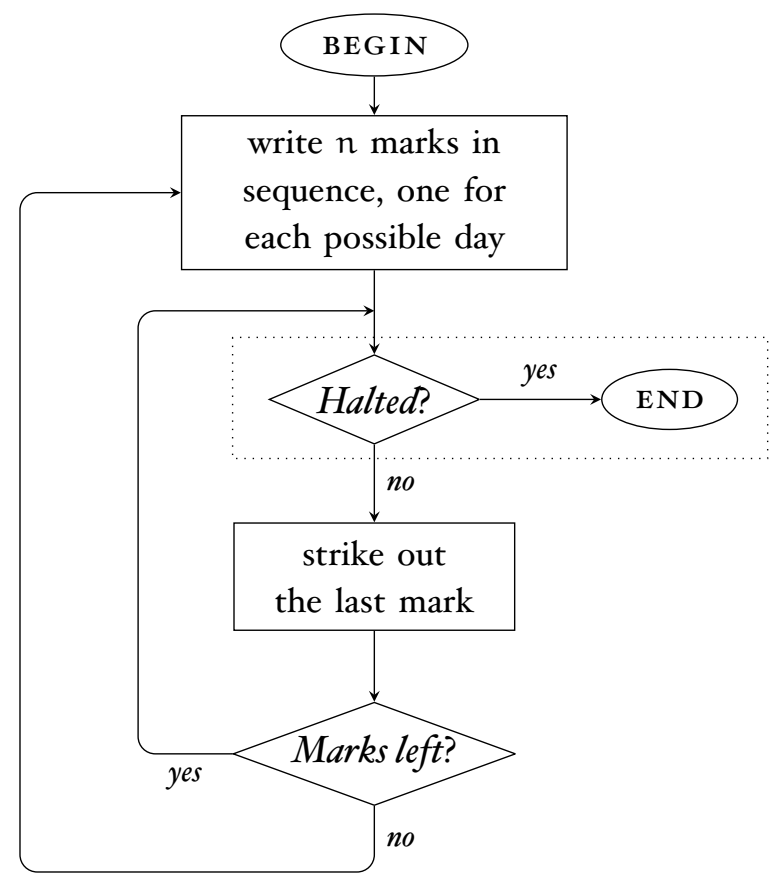

Figure I: a process of elimination

ize that randomization or something else has been used) on Saturday evening she will be in a position to anticipate that Saturday was not selected by lottery. And if not Saturday, then Sunday; and the nonhalting phenomenon reemerges. Hence it does not help Brenda to realize that the original procedure does not terminate. For any alternative procedure, even a randomizing one, will also suffer from the exact same deficiencies. The announcement makes any projections on Brenda's part unstable, because it profoundly preempts decision procedures that do not give full measure to the fact that an oracular statement has been made.

We will be reminded no doubt that W. V. O. Quine solves this problem, showing us that all of Brenda's perplexities can be laid to rest if only she will give up the assumption, having made it without warrant, to the effect that Alfred will indeed keep his promise, and will do so in the knowledge that she (Brenda) knows he will 7 I reply that Brenda is making no such assumption. What Brenda is doing, at every stage of deliberations, is testing a certain hypothesis, either the Saturday hypothesis (according to which Alfred will visit on Saturday) or the Sunday hypothesis, to determine whether there isn't something wrong with it-namely, whether it is consistent with his speech act announcing a visit. The trouble is that she finds each hypothesis wanting, in different ways, in different stages of her analysis. Of course, she can always

\footnotetext{
7“On a Supposed Antinomy," Ways of Paradox, Cambridge (Harvard University Press, I966).
} 
conclude that he will not come as promised, or simply that she has no knowledge that he will. But that she must reach this conclusion is precisely what calls for explanation, in light of the wealth of what would ordinarily be viewed as evidence to the contrary. Brenda can avoid her troubles only if she will forfeit her right to try to work out the weekend's prospects from the available cluesone wants to say even the clues thrust upon her. But saying this much does not explain what it is about that set of clues, or about Brenda's position vis-à-vis the puzzle of Alfred's weekend visit, compels forfeiture of that right.

Many beliefs and judgments-many more than one would acknowledge off hand-rest on anticipations of other individuals' reasoning processes. Some of these beliefs are reciprocally dependent, because they involve anticipations of each projecting individual by the other. I will refer to judgments and beliefs exhibiting this type of mutual dependence as common-perspectival. Commonperspectival beliefs and judgments are the result of tacit, and typically also subconscious or unfelt, intellectual negotiations - to make use of well-established terminology of strategy theory. Formation of common-perspectival beliefs cannot occur in an environment in which expectant selves form no anticipations of how other selves may be conducting deliberation. Rather, formation of common-perspectival beliefs occurs only among individuals whose intellectual lives are known to be at least partly transparent to others, and known to be known to be partly transparent-individuals whose intellectual lives, as well as their public lives, are interdependent $\left.\right|^{8}$ And in fact one might even say, and not without precedents, that rationality is a form of anticipatability-and therefore a form of transparency. The judgment of entities that live in a community of mutually anticipatable others is interdependent and common-perspectival. This is why members of such a community can use context to communicate, and need not say explicitly everything they mean to communicate through speech.

Why is Brenda (in particular) unable to bring deliberations to a halt? My explanation will be simply that the deliberations she aspires to consummate require the possibility of negotiating common-perspectival beliefs, that such negotiation requires compatible aims, but that the aims of Alfred and Brenda are incompatible. And these facts shall explain too Alfred's precisely symmetrical position vis-à-vis a belief about his own visit. But Alfred's position is different when it comes to his aim: his aim has an advantage over Brenda's, as I will now explain. Projections are typically produced against an inventory of aims and purposes. Otherwise there would be no reason to favor projecting concerning one potential episode in human affairs rather than another. I shall say that two aims come into accidental conflict when both can be satisfied together in some logically possible set of circumstances, but cannot both be

\footnotetext{
${ }^{8}$ This idea is brilliantly treated by Thomas Schelling, The Strategy of Conflict (Cambridge: Harvard University Press, 1960), and deftly built upon by David Lewis, Convention (Cambridge: Harvard University Press, 1969).
} 
satisfied in the actual circumstances. (It is logically possible, for example, that each of our aims to win a million dollars in a lottery be satisfied, but not that each aim be satisfied under circumstances in which we enter the same lottery with only one one-million-dollar prize.) And I shall say that two aims are in direct conflict when, logically speaking, both cannot be satisfied together under any circumstances.

Brenda of our story acquires the aim of anticipating the day of Alfred's visit, upon receiving from Alfred himself the announcement of his intention. Alfred, in announcing his intention, has the aim that she shall not anticipate the day, knowing that the announcement will nonetheless foster in her the aim to do so. It is in fact with the aim that she be unable to form an anticipation that he makes the announcement. It is not possible that both aims be satisfied together. Thus they are in direct conflict. Alfred bimself creates this conflict by (I) establishing his own aim that Brenda should be taken by surprise, and (2) announcing his intention as he does, thereby fostering in Brenda the aim of anticipating the day of the visit. Finally, the announcement itself, and Brenda's receiving of it, create conditions which favor achievement of Alfred's aim, but not Brenda's. And the fact that Brenda can have full knowledge of all we have said here does not improve her situation in the minutest degree.

Thus we may explain Brenda's difficulties in terms of her conflicting aims, which cause the fabric of common-perspectival beliefs to unravel. These snags in the fabric of common-perspectival belief often favor the satisfaction of one aim over another. In our story, Alfred's aim is favored, since his is-not that anyone concerned (even himself) shall have grounds for anticipating the day of the visit-but rather that Brenda in particular should not be in possession of such grounds. (And, incidentally, Alfred cannot undermine Brenda's potential foundations for such a belief without undermining his own as well. $\mathrm{He}$, not unlike Brenda, can know the day of his visit only in the process of making that visit.)

However, the fact that the beliefs in question are common-perspectival is not the problem. Instead it is the aims on which they must be negotiated, which are directly in conflict. Contrast our current case with the case of two surprise-averse friends, one of whom says to the other: "I will pay you a visit one day this weekend, such that you will be able, without further information, to anticipate my visit the day before." The promise maker makes the announcement with the aim that the promise recipient should be able to anticipate the visit. The promise recipient also has this aim, or could have it. There is no conflict, since both know that if the promise maker stays away on Saturday, both will formulate a projection, through the route of anticipating reciprocal projections, of a Sunday visit. There is no instability, because there is no direct conflict.

And so the problem for Brenda, and Alfred too in consequence, vis-à-vis a judgment as to when Alfred's surprise visit shall occur, springs from the existence of directly conflicting aims, whose presence prevents successful negotia- 
tion of expectations. Brenda can prevent her tortured reasoning only by either withdrawing from, or else refusing to enter into the enterprise of projecting. And she does either one at the cost of having no opinion whatever on the day of Alfred's visit, and so being susceptible to surprise. This is Alfred's supreme achievement. (Talk about doing things with words!) We can explain, therefore, how Alfred's announcement of his intentions precipitates the situation it foretells, where in its absence there would not have existed even the incentive to formulate a projection.

I have purported to explain Brenda's difficulties through bringing to attention a pair of conflicting aims - in other words, by declaring that the difficulties she is experiencing spring from the ordinary conflicts of day-to-day life. But, the objection might go, isn't it enough to cause the very same trouble that Brenda should simply believe the statement conveyed in Alfred's utterance to be true-for whatever reason? Isn't the trouble caused simply by the logical nature of that truth-bearer? So have I not unnecessarily added to the explanation of her difficulty that Alfred is trying to bring the promise about by means of the promise itself? No, for two reasons. First, it is precisely the fact that Brenda knows of Alfred's intentions through Alfred's own mouth, which makes her difficulties of reasoning so robust. For if we are allowed to assume that Alfred has no aims to bring the promise about through its very utterance, then we can sketch the story in such a way that there are for Brenda no difficulties whatever of reasoning.

Consider for example a case in which Brenda learns of Alfred's intention to pay her a surprise visit on the weekend by overhearing a secret conversation between Alfred and Claire. On this scenario, Brenda, although still without grounds for anticipating the precise day, is nonetheless without grounds for eliminating any eligible day. But she can nonetheless be certain that, if Saturday evening arrives and Alfred has not yet paid the visit, she can then be confident he will show up on her doorstep the following day. And this is precisely the sense in which Brenda's coming to learn of the visit through Alfred's own mouth gives her no information from which to work out the day, and leads her instead to aim at a goal unattainable in her circumstances. Moreover she loses, whereas she does not lose in the case where she learns of Alfred's intention through overhearing the conversation with Claire, the ability to anticipate a Saturday evening anticipation of a Sunday visit.

Second, the objection that I have added unnecessarily to explanation of the phenomenon presupposes-correctly, as it happens-that the difficulties of reasoning result from activities of deduction. However the activity of deduction, according to this objection, is a strictly syntactic affair, governed exclusively by rules of inference; deduction is nothing but a mechanical procedure of applying permissible rules of inference. This is false. For one thing, deduction involves a screening of premises as to consistency and possible truth, which mere application of inference rules does not. In deducing one tests the integrity of the premises under use, via the conclusions that flow from them. 
In fact, an assessment of the consistency of a certain promise with realities of a practical nature, of which she is so painfully aware, is precisely what Brenda of our story is at pains to conduct. More importantly, deduction is itself a goaloriented enterprise, aimed at deducing a particular conclusion in which one anticipates being able to put one's faith, not permissible ones haphazardly.

\section{EXPRESSIVE ACTS: TOWARDS A SPEECH ACT DOCTRINE}

I shall suppose that each belief is acquired, by its possessor, with at least one aim or purpose in mind. Each belief is acquired for a reason. (In the case of a perceptual belief which, to all appearances, is uninvited by its host, I will say that it is acquired for the-possibly subconscious-purpose of autonavigation.) I shall say that a belief is self-defeating when one or more aims for which it is acquired are made impossible to achieve by the very existence of that belief. In such cases we can also say that the belief enters into direct conflict with an aim-in fact, with that aim for which it is acquired. For example, my belief, to the effect that a certain truth-bearer is true, is self-defeating if I acquire it whilst performing an inquiry I believed would lead to its refutation. (Nonetheless embracing it might be the honorable thing to do, in light of evidence I come eventually to possess.) So not only is it the case that aims can come into direct conflict with one another, but they can come into direct conflict also with beliefs. I shall call an aim or aspiration self-defeating when every potential means to its pursuit renders it unachieved, so that its very existence ensures its nonfulfillment.

I shall suppose further that each speech act (indeed, each judgment) is performed with at least one aim in mind. And I shall call a speech act self-defeating when its performance conflicts with one or more aims in the service of which it is performed. (Jean Buridan, it will be recalled, held a related thesis: he maintained that a sentence, in addition to asserting whatever it does explicitly, also asserts its own truth. So that any sentence that explicitly asserts its own falsehood is straightforwardly contradictory and hence false.9 I am not maintaining so bold a thesis about sentences. My thesis is about the preconditions of declarative speech acts.) Speech acts, like beliefs, also can enter into conflict with aims.

Let us now turn to the Liar. If it's true, it's false; and if false, true. A natural conclusion might be that no Liar sentence is ever true or false-and that therefore the assumption that the privation of truth is falsehood and the privation of falsehood truth, is itself false. There must be a middle ground between true and false. Is this middle ground a truth value? There is a very strong temptation to say yes, there is an intermediate truth value: neither-truenor-false, or a suspension between the two. (Cottage industries are founded on acts of yielding to temptations such as this one.) However, those who yield

9 J. L. Mackie, Truth, Probability and Paradox (Oxford: Clarendon, 1973), Chapter 6, explores this proposal at some length. 
to temptation presuppose that the problem with the Liar can be addressed through application of philosophical ointments like intermediate or suspended truth values. Whatever one thinks of intermediate or suspended truth values, the move in this direction, vis-à-vis the Liar, is just too hasty.

I agree that the privation of truth is not falsehood, and neither is the privation of falsehood truth; but I affirm these things on the grounds that neither stones nor apples are true, and that this does not imply they are false. So there is a middle ground, after all, but the ground does not consist of an intermediate or suspended truth value. Instead it consists in embracing the idea that truth and falsehood are proprietary properties of something besides sentences or sentence tokens-the truths or falsehoods, the facts or fictions in their own right - and only by a courtesy properties of whatever actually gets to express a fact or fiction. I shall simply refer to that which bears truth or falsehood, in the proprietary sense, a truth-bearer, and acknowledge that it is no sentence or sentence token. Here we shall be remarking on the ways in which truthbearers enter into human endeavors, not on their essences or natures. We shall concern ourselves with the metaphysics of expressing truths, and thus with the metaphysics of an enterprise, not with the metaphysics of the entities, as such, which are the objects illuminated in that enterprise.

My proposal is to exclude as simply ineligible of truth value things that don't express truth-bearers. And thus to view the Liar sentence or statement as a stone or bludgeon: you can swing it, pitch it at a colleague, beat folks over the head with it, but never press it into service of making a true or false statement. The proposal is that the Liar sentence is useless except in the ways of kitchen knives and bludgeons, because it can never, under any circumstances, express either a truth or a falsehood. But now we require an explanation why not, since well-formed, grammatical sentences, when uttered under normal conditions, ordinarily do express truths or falsehoods.

Now the proposal for which I'm agitating, according to which not all sentence tokens express truth-bearers, is not new $[0$ Neither is the proposal that some sentence token is neither true nor false because it fails to express a truthbearer. The latter dates back at least as far as Frege ${ }^{m}$ And A. N. Prior offers an analysis that bears a decided family resemblance to my own. ${ }^{12}$ His view, inspired by examples discussed in the middle ages by the likes of Jean Buridan, is that one cannot (oddly enough) say what it looks like one is trying to say by way of a Liar sentence. But he does not explain why not. In a similar vein, L. J. Cohen argues that certain utterances cannot be true under certain circumstances,

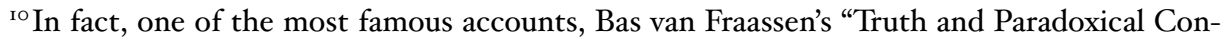
sequences," in The Paradox of the Liar, Robert L. Martin, ed. (Yale University Press, 1970, 13-24), puts this proposal forward on the ground of a truth value gap.

${ }^{\text {II }}$ And it is fleshed out in a very different way by John Kearns, "Some Remarks Prompted by van Fraassen's Paper," in The Paradox of the Liar, Robert L. Martin, ed. (Yale University Press, I970, 47-58).

ז2 "On a Family of Paradoxes," Notre Dame fournal of Formal Logic 2 (I96I), I6-32.
} 
but (again) he gives no explanation of this fact ${ }^{13}$

One consequence of the idea that not all sentence express truth-bearers is that tokens of the same linguistic forms might stand in different relations of expression to the truth bearers. This is an idea that has been advanced in recent scholarly treatments. And many justifications of truth value gap accounts of this type defend the view by saying that one can think of the "gapped" statements as failed assertions ${ }^{14}$ But again: why the failures?

My contribution to this discussion will be to require specific explanations of why a particular sentence token fails to express a truth-bearer, and to allow that pragmatic and metaphysical considerations might be a rich and fundamental source of such explanations. The reason for failure in one case can differ from the reason for failure in another. So if it is true that the Liar statement fails to express a truth-bearer, why does it fail? Here is where what I am proposing vis-à-vis the Liar is new.

Someone might simply insist that every well-formed, grammatical sentence, whenever actually given utterance, expresses a truth-bearer. This is a mistakeand as I've been insisting, the fundamental one. If I ask you to look up from this page and say, on a cue: "The horse is lame," you will not express a truthbearer thereby, in spite of having uttered a perfectly grammatical sentence, one whose terms we could agree are unmarred with linguistic vagueness, and one which under the right circumstances will express a very handsome truth-bearer indeed. The reason that it does not do so on this occasion is that the subject phrase in your utterance does not refer: it has no suitable context with which to work, although on another occasion it might have had. So the sentence as a whole can bear no truth value; on my account it fails to express a truth-bearer, despite being transparent to the understanding. (And so a second moral of this inquiry is to notice a fundamental distinction between an act that engages the understanding, and one that goes all the way to expressing a truth or falsehood.)

Therefore we must acknowledge that expressing a truth-bearer is a conditional achievement, even when once the understanding has been engaged in the appropriate declarative way and all linguistic ambiguities are cleared away. It is ordinarily accomplished with a minimum of effort going into fitting the right sentence to the given context. But the fact that expression of a truth-bearer is easily achieved under normal circumstances, does not eliminate the potential for failures through mismatche between context and sentence. This fact then, that expressing a truth-bearer is a conditional achievement, brings to focus the expressive act - the act of directing attention to a truth-bearer through some in-

\footnotetext{
13“"Mr. O'Connor's 'Pragmatic Paradoxes," Mind 59 (1950), 85-87.

${ }^{14}$ See especially the work of H. Gaifman, "Paradoxes of infinity and self-application, I," Erkenntnis 20 (I983) I3I-I55; "Pointers to Truth," Fournal of Philosophy 89 (1992), 223-261; "Pointers to Propositions" in Circularity, Definition and Truth, A. Chapuis, ed., (New Delhi, 200o). T. Burge has an indexical account to the same effect: "The Liar paradox: Tangles and chains," Philosophical Studies 4I (1982), 353-366; "Semantical Paradox," Journal of Philosophy 76 (1979).
} 
strumentality, customarily but not exclusively through use of language $\sqrt{15}$ The successful expressive act-successful, to be more specific, in directing attention to a truth-bearer-will then be either true or false, derivatively, according to whether the truth-bearer to which it directs attention is true or false.

Every success in the endeavor to express a truth-bearer, and thereby to predicate or describe, succeeds in drawing attention to a truth-bearer. But not all failures to express truth-bearers are likely to be failing in the same ways. For (as usual) there are very few ways for things to go right, but many more ways in which they can fail to do so. So what explains the Liar's failure to express a truth-bearer? One famous answer is that the Liar is a statement referring to itself. But truth-bearers are not allowed to do this-at least not truth-bearers expressed in part by use of the truth predicate. And we may be able to offer some reassuring reasons for ruling out self-reference by truthbearers, having to do with how the truth predicate is to receive philosophical treatment, via a favorite tool of analysis (set theory, for example). This reassurance is rather peculiar, in that it allows the tail (the theoretical apparatus for explaining what is done through application of the truth predicate) to wag the dog (the phenomena itself of drawing attention to truth-bearers). And in any case, self-reference is not always sufficient for paradox. As statements go, many of the self-referring type are neither impermissible, nor problematic. The sentence 'The present statement is composed in the English language' is permissible, true, and possibly even analytic ${ }^{{ }^{16}}$ So, at least on the face of things, self-reference, either all by itself or in combination with the truth predicate, is not sufficient to generate the problem to which the Liar directs attention. $\sqrt{17}$ At this stage it helps to put the Truth-teller:

(TT) (T) is true;

alongside the Liar, and to note that there are problems with the latter that are not shared by the former. And that obviously neither problem is due to self-reference.

\footnotetext{
${ }^{15}$ I am using the term 'expressive act' as J. Searle uses it in "Austin on Locutionary and Illocutionary Acts," Philosophical Review 77 (1968) 405-424. By way of an illuminating contrast with my view, see J. Kearns, "Sentences and Truth-bearers," The Logical Enterprise, A. Anderson, R. Marcus and R. Martin, eds, (Yale University Press, 1975, 6I-84) which upholds the principle that truth and falsehood are proprietary properties of expressive acts; cf. also his "Expressive Logic of Supposition and Assertion," Notre Dame fournal of Formal Logic 1997). (Kearns' use of the term 'expressive act' is slightly narrower than mine: all his expressive acts are instances of mine, but the reverse is not also true.)

${ }^{16}$ To see that it is analytic we perhaps require an illucutionary logic. John Kearns' "Expressive Logic of Supposition and Assertion," op. cit., puts forward an account which evaluates this sentence as analytic.

${ }^{17}$ S. Kripke, "Outline of a Theory of Truth," Fournal of Philosophy 72 (1975), 690-716, shares this point of view. And S. Yablo presents a version of the Liar explicitly without self-reference, in "Paradox Without Self-reference," Analysis 53 (1993), 25I-252. The basic technique of substituting infinity for self-references generalizes to all "self-referential" paradoxes: R. Sorensen, "Yablo's Paradox and Kindred Infinite Liars," Mind IO7 (1998), I37-I55.
} 
The Liar is conflicted all right. But not in the way a statement which has the shape of ' $\mathrm{P}$ and not- $\mathrm{P}$ ' is conflicted. The latter is contradictory, in that each half of the thing contradicts the other half, so the whole is never true. Nonetheless, statements of shape ' $\mathrm{P}$ and not- $\mathrm{P}$ ' are capable of expressing truthbearers, which as it happens are impossible to satisfy, because they succeed in describing, albeit falsely. None of this is true of the Liar. Where does conflict in the Liar lie? And why does this conflict prevent its expressing a truth-bearer?

I am maintaining that linguistic expressions do not bear truth and falsehood in the proprietary sense, and have designated as "truth-bearers" those entities that do so. And I am furthermore declaring that expressive acts-acts of directing attention to truth-bearers, normally through use of languageshall also be susceptible of truth and falsehood, but only by a courtesy, as the truth-bearers to which they direct attention are either true or false. I shall now, in addition, suppose that each expressive act is put forward in the service of an aim to describe or judge, among the many more specific aims that expressive acts may serve. (Now some expressive acts are conditional in form: someone might say, for instance, "If this sentence is false, then the moon is made of green cheese." We might wish to pronounce that this is no expressive act-that it amounts less to a saying of something, as to a making of a wager. My own inclination is to say that it amounts to an act of wagering too, but only through serving as a performance of a certain expressive act. However this issue need not detain us. Nothing hangs on it vis-à-vis diagnosing the Liar. For the Liar is a simple declarative sentence, and will qualify—if at all—for only the most basic of expressive acts.)

All this amounts to asserting that it is individuals, or communities of individuals, who do the semantic work of referring to things and describing and judging. And to asserting also that words and sentences by themselves do nothing but stir the air, or just lie about where set down. Linguistic materials are mere instruments that aid in the enterprise of describing. This is now the speech acts doctrine for which I am agitating ${ }^{18}$ According to this doctrine, the speech act is the fundament of semantic phenomena, not the truth-bearers nor the parts which compose them (whatever these shall turn out to be). My view, then, is in three parts. (I) The entities that bear semantic properties in the proprietary sense are not strings of symbols in a human language. (2) Linguistic media does not, all by itself, accomplish semantic work of the likes of directing attention to truth-bearers; they are nonetheless means to achieving a variety of semantic tasks. (3) The semantic work of describing and referring, done through language as an instrument, is the work of individuals with aims of describing and referring. There can be no directing attention to a truthbearer without a concrete, real-time aim to do so, as there can be no success

\footnotetext{
${ }^{\mathrm{r}}$ Thus, whilst Barwise and Etchemendy, op. cit., utilize the notion of 'context', they are not providing a speech act treatment of the Liar. Their notion of context is entirely formal, and makes no contact whatever with the ordinary players of real life.
} 
without an aspiration to it. And the same goes for referring. For describing and referring are inherently conditional achievements, and as such cannot be accomplished by entities (for example abstract entities like linguistic materials) that cannot by any stretch of terminology sustain aims.

It may be objected that sentences like "Two plus five equals seven," or eternal sentences like "It is raining in Buffalo, New York, on April I, I997," describe perfectly well, and do so successfully, all without the aid of any aims or contexts, provided the meanings of terms in the language have been fixed. Thus that my proposition (3) above must be incorrect. I reply that this objection papers over the fact that meanings of terms in a language cannot be fixed independently of the aims of those individuals who originated the terms and therefore the language. Thus that even eternal sentences cannot serve, in themselves, to direct attention to truth-bearers, but require the support of aims, however removed from production of the eternal sentence these might be. The general condition of sentence tokens is that they require the help of aims, however remote from the conditions under which they are produced, in order to direct attention to a truth-bearer. Sentence tokens universally depend on language users for the semantic properties, although the immediacy of this dependence may vary.

Now, none of what I'm saying here is inconsistent with the semantic conception of truth as articulated by Tarski, in which the Schema $(T)$ attaches truth value to a sentence upon a certain condition. But it is inconsistent with the view, articulated perhaps most audaciously by Horwich, according to which truth is a proprietary property of sentences, and that $(\mathrm{T})$ defines it. For on an account such as I envision, the fundamental expressive act is the act of judgment, and all other expressive acts are dependent upon it. Moreover, what I'm saying is emphatically not platitudinous. And so it is quite possibly inconsistent with any of the reigning doctrines on truth: correspondence, coherentism and deflationism. Indeed I suspect that it is inconsistent with all of them, but this is not the place to explore the question.

The aim to describe or judge, which supports a piece of language in directing attention to a truth-bearer, need not be an aim to describe or judge correctly or truthfully. If a speech act describes its subject matter correctly (that is, truthfully), I shall say that the aim to describe or judge is thereby achieved; and I shall say the exact same thing if the speech act describes its subject matter incorrectly (that is, falsely). In the first instance the speech act will have expressed a true truth-bearer, in the second instance a false one. In both instances the aim to describe is achieved in the same way-by successfully drawing attention to a truth-bearer. If, on the other hand, no describing takes place, I shall say that the aim to describe is unachieved. And of course an aim to describe will be self-defeating, in keeping with the earlier definition of aims being self-defeating, when every potential means to its pursuit renders it unachieved. The Liar, as I will show, is plagued with an aim that is unachievable to this degree.

Now the Liar sentence is not normally put to gainful employment in real 
life: it is not normally a means to performing any familiar speech act. (Not surprisingly, with good reason.) But we can imagine it being uttered. I will argue that a speech act consisting of a statement of the Liar sentence necessarily involves a self-defeating aim, and that this is the reason why it cannot express a truth-bearer. The norms of assertion cannot be satisfied on any occasion of utterance of the Liar sentence, so that Liar can never succeed in expressing.

The speech act which consists in uttering the sentence 'The present statement is not true' is (according to my account) put forward in the service of an aim to describe. More specifically, it is put forward in the service of describing itself not true. This aim is unachievable in the sense that every means to its fulfillment renders it unfulfilled. Hence it is self-defeating. Here is why.

There are just two configurations of ways in which the Liar's aim to describe itself as not true might be pursued: (I) by describing itself correctly as not true; and, as discussed above, (2) by describing itself incorrectly as not true. Neither configuration fulfills the aim. For suppose that the Liar succeeds by the first method-that is, suppose it succeeds in describing itself correctly as not true. Since it is correct, then it is not true. But if not true, then incorrect after all, and so the aim was not fulfilled through a correct description as supposed. Against the assumption to the contrary, the speech act in question does not succeed in describing itself correctly as not true. Suppose, on the other hand, that the Liar succeeds by the second method-that is, suppose it succeeds in describing itself incorrectly as not true. If it's an incorrect description, then it's not not-true (according to what the Liar says). There are then two possibilities: (a) it is true, and (b) it is ineligible of truth-the truth predicate does not apply. If (a), then it is not true, as this is what it says, and this contradicts the assumption of truth. So it cannot be (a). If not (a) then-by the assumption it is either one or the other-it must be (b). However achieving (b) is not a means of describing at all, for this contradicts the original assumption (2), to the effect that the Liar succeeds in some sort of describing. Hence neither (a) nor (b) is true, and hence the assumption (2) is false as well. The Liar cannot succeed in describing at all. The Liar, as a speech act, involves a self-defeating aim. Therefore it is suited only to the sort of uses for which a bludgeon too is suited: it serves non-expressive purposes only. But why does being self-defeating, when this property is possessed by a speech act, deprive it of truth value? We do not yet have an account of this matter.

There is something deeply wrong with self-defeating aims. Consider, for a first example, the aim to be spontaneous. Consider for a second the aim (for example in the case when it is the only aim an individual possesses) to fail to achieve all one's aims. It is not psychologically impossible to be possessed of such aims. Many people speak, with some attempt at levity, about the first. And many self-hostile individuals seek (perhaps subconsciously) to undermine certain of their own aims. And since it is not psychologically impossible to have such aims, it is not logically impossible either. But is my (only) aim, to fail at my only aim, even in the market for being achieved? Suppose I do achieve it. 
This cannot be a form of success, since I also fail (because in succeeding I fail to achieve my only aim). Suppose, to the contrary, that I do not achieve this aim. Then I succeed after all, but at the price of not succeeding. Once again, this cannot be viewed as success. Self-defeating aims are imprudent. They waste precious resources, cognitive and otherwise. For they cannot be achieved, but at the same time expend precious resources. For an aim to be in the market for being achieved, therefore, it must satisfy the demand that it not be self-defeating, since only then will it be worth including in one's inventory in the first instance. It cannot be denied that this is a basic practical imperative-so basic in fact that it's hardly worth the trouble of stating, not to mention awkwardly simpleminded. A speech act that consists of uttering the Liar statement cannot meet this basic, simple-minded imperative. A Liar statement aspires to describe itself in a particular way. But achievement of this aim would guarantee failure to achieve the aim. Hence the aim is unachievable. Hence a speech act utilizing the Liar cannot express a truth-bearer.

It's not that there's something mysterious or deeply problematic about the enterprise of describing, thought of in terms of directing attention to truthbearers, that a speech act consisting of utterance of the Liar cannot accomplish it. It's just that not every statement can perform the job. By the same token, not everyone may achieve a novel authored by Tolstoy; none but Tolstoy may achieve even the aspiration to it (as we may indeed wish to insist). Thus the Liar does not reveal an infirmity with the workaday conception of truth, according to which true statements describe correctly, so that we must agitate for repair or replacement of it by a more resilient specimen, invulnerable to Liar statements. The Liar reveals only that not every statement can achieve the function of describing, because not every statement is capable of directing attention to a truth-bearer. Directing attention to a truth-bearer, as we must acknowledge, is a conditional achievement under the very best of circumstances.

As a speech act, the Liar has the dubious distinction of being incapable of this achievement under every potential circumstance. It cannot succeed even in the aspiration to describe. For an assertion to be susceptible of being true, it must satisfy the condition that its aspiration to describe be non-self-defeating. Interestingly, an assertion of the Truth-teller does not obviously fail to meet this practical demand, whereas the Liar fails in a spectacular way. Nonetheless, a token of $(\pi)$ is arguably also a waste of resources, so may be considered imprudent to perform, but possibly not for the same reasons that statement of the Liar wastes resources. Hence the difference to which we pointed earlier between the two statements. The point for now is simply that many statements compete for the achievement of describing, most without success. Every such achievement is successful in the same way. But the unsuccessful attempts are unsuccessful in different ways. 
It is worth remarking that J. L. Mackie ${ }^{\mathrm{ID}}$ seems to endorse an account (that he attributes to remarks of Gilbert Ryle) of the failure of Liar to express a truth-bearer that might be regarded as a version of my own. He says that there is nothing for Liar's truth or falsehood to amount to: when once the "instructions" (or "meaning rules") for evaluating something as to truth and falsehood have been applied, nothing remains that can be evaluated-on any grounds - as to truth. As Mackie puts it, Liar "raises no issues. 20 He further remarks that the Truth-teller suffers from this same problem, and approves of accounts that diagnose the same malady in both instances.

Similarly H. Herzberger diagnoses the same defect (one that is further elaborated by S. Kripke) in Liar and (TT): neither one is grounded, by which is meant that there is nothing substantive-no independent fact about the world-that might make either of them true or false ${ }^{21}$ Now, obviously a ban on ungrounded sentences would be too broad: "in semantics it wreaks havoc, banishing the laws of logic on their naïve construal (as statements about all statements including themselves) along with the general principles of semantic theory including the grounding condition itself., ${ }^{22}$ Similarly, it is not clear what Mackie's "raising an issue" amounts to, or what it or grounding might have to do with expression of truth-bearers.

But I would say, against fans of groundedness, that the problem with (L) is not so much that nothing remains to be evaluated, when once the "instructions" for evaluating something as to truth have been followed, but rather that applying those instructions, in the first place, is problematic in the case of the Liar. And that they are not problematic, and spectacularly so, in the case of the Truth-teller. Nothing goes amiss if we should assign it a truth value of True; and likewise also nothing goes amiss if we assign it a truth value of False. So while ( $\Pi$ ) raises no issues, even so it violates no preconditions for a successful description, where by contrast every instance of the Liar does. And so there is an important asymmetry between Liar and ( $T$ ), that an account of groundedness would fail entirely to diagnose. Whatever Liar misses out on, Truth-teller enjoys to embarrassment, and this point itself must not be missed out.

\section{ORIENTATIONS TOWARDS THE ENTERPRISE}

I am claiming that for any Liar utterance, circumstances will conspire to bring it about that there is no truth-bearer expressed where there might seem to be, because the relevant aim is self-defeating. But someone might complain that at least some self-defeating aims are downright paradoxical as well—downright

\footnotetext{
${ }^{19}$ Truth, Probability and Paradox (Oxford: Clarendon, 1973), Chapter 6.

${ }^{20} \mathrm{Ibid}, 260 \mathrm{ff}$.

${ }^{21}$ Herzberger, "Paradoxes of Grounding in Semantics," Fournal of Philosophy 67 (1970) 145-67; Kripke, "Outline of a Theory of Truth" op. cit.

${ }^{22}$ Herzberger, 15I. Circumscribing the ban on ungroundedness turns out to be surprisingly difficult, as Sorensen (Vagueness and Contradiction, Oxford: Clarendon, 200I, p. I68 ff.) documents.
} 
logically conflicted. A prime example is surely the aim to fail at my one and only aim: if it were merely self-defeating, then surely everyone with that aim would fail at it. But to do so is to succeed after all. And this is paradoxical, and not merely self-defeating. So I must have it just backwards, at least visa-vis this particular self-defeating aim: it is precisely because circumstances conspire to bring it about that there is no aim where there might (at least to the likes of me) seem to be one, that we have such trouble deciding whether the purported aim is achieved. The aim is nonexistent, because there is a logical conflict in supposing there is one. Why suppose the Liar is any different? It is trouble with logic, as far as it goes. No more and no less.

I may reply—as I hereby do-that this complaint simply recapitulates the position I wish to challenge, without offering argument on the other side; it only points out a certain parallelism. But this reply invites the retort that I am doing no more for my side: I too am simply insisting on my position without going further. I think, however, that one can do better in replying to the criticism. The better reply is to insist that the two positions are not merely parallel. There is a clear asymmetry. My position accepts aims at face value, and is more skeptical about where there are truth-bearers; the opposition does the reverse. But this is a difference that makes a difference, from the point of view of philosophy more broadly conceived.

The position that accepts aims at face value takes a certain body of facts as data-namely, concrete phenomenological experience, or what we view as open to ordinary observation, difficult to challenge except through Cartesian devices. The other side takes (roughly) certain grammatical sentences as data for identifying the non-contradictory truth-bearers. These positions are orders of magnitude apart, philosophically speaking. The view that is prepared to declare the nonexistence of an aim, where there seems to be one, is prepared to let the tail-the theory of truth-bearers-wag the dog of experience. It is prepared to count two possible worlds, which differ only insofar as in the first I embrace the aim to fail at my one and only aim, whilst in the second I am thoroughly aimless, as completely indiscernible, at least insomuch as aims are concerned. This position, it seems to me, is thoroughly indefensible. Here is why.

Truth-bearers are theoretical entities. They are entities which help us explain a wide range of pragmatic, communicative, grammatical and logical phenomena, without being themselves subject to direct observation. In other words, truth-bearers (at least on the view I am propounding) are bearers of truth value-whatever these happen to be; and it remains to be worked outas a matter of philosophical theory-what the truths are that are to be borne by truth-bearers. Truth-bearers, on this view, function to help us count and distinguish our possibilities, by helping us keep track of how worlds might differ. As such they are purely bookkeeping devices. But if this is right, then we had better not allow certain purely unreflective intuitions about truth-bearerssuch as whether or not one is expressed via such-and-such an utterance-to 
generate uncontested data that a theory of logic has subsequently to explain. And this is precisely what my opponents would have us do. They begin with data about what we find meaningful—linguisitically, grammatically—and build philosophies up to explain these data. It is no wonder, therefore, that they view my position as getting the order of analysis backwards. ${ }^{23}$

By contrast, I am supposing that we ought to assemble the theoretical entities of logic - the bookkeeping truth-bearers—so as to maximize explanation of observations and experiences. This suggests we be more prepared to take aims at face value than intuitions about truth-bearers. And it moves us in the direction of taking seriously the economy of aims, and away from the stancetaken in an unreflective moment- that truth-bearers must correspond in a simple way to the sentences sometimes used to draw attention to them.

\section{CHAINS AND MORALS THAT SUSPEND FROM THEM}

Another version of the Liar requires treatment at this point ${ }^{24}$ A critic may insist that a statement made using

(B) Sentence ( $\mathrm{L})$ is not true,

if it expresses anything at all, expresses the same truth-bearer as (L). And if $(\mathrm{L})$ cannot be true, neither can (B). But that (B) is my own theory on this matter! Hence my own theory cannot be true, since it cannot express a truth-bearer! Or, contrariwise, since (B) is expressible, and eligible of truth after all, then so must ( $\mathrm{L}$ ) be as well.

I reply simply that speech acts consisting of utterances of $(\mathrm{L})$ are not, as speech acts, identical with speech acts consisting of utterances of (B), that (B) can be utilized to express a truth-bearer while (L) cannot. To see that $(\mathrm{L})$ and (B) are not identical speech acts, one need only note that an act which consists in uttering sentence $(\mathrm{L})$ refers to sentence $(\mathrm{L})$ itself, or to a token of sentence $(\mathrm{L})$, while one which consists in uttering sentence (B) is not referring to a token of the sentence being used (namely, sentence (B)), but to a token of a different sentence (namely, sentence (L)), which refers to itself ${ }^{25}$ Thus an act using sentence (L) both mentions and uses sentence (L), while an act using sentence (B) does not use but only mentions sentence (L). This is a metaphysical difference between the two acts, that makes a difference indeed. The latter act is identifying a structure that does not express a truth-bearer, and saying about it (truly, as it happens) that it does not express a truth-bearer, while the former refers

\footnotetext{
${ }^{23}$ The opposition view rears its head also in Bonevac, cited above.

${ }^{24}$ This is sometimes referred to as the infinite chain version, by, for example, Burge (op. cit.), Sorensen (op. cit.) and Yablo (op. cit.).

${ }^{25} \mathrm{~A}$ strategy with similar structure is deployed, but with a different result, by H. Gaifman, "Operational Pointer Semantics: Solution to the Self-referential Puzzles I," in Proceedings of the Second Conference on Theoretical Aspects of Reasoning About Knowledge, ed. M. Vardi (Los Altos, Calif.: Kaufman, 1988), 43-6o.
} 
to the same structure, and also attempts to use that structure to express a view to the effect that the structure under use, itself, either expresses a false truthbearer or does not express a truth-bearer at all. Thus (L) and (B) give rise to different acts. And only (L) is doomed to failure as a speech act, for as a speech act it rests on a self-defeating aim. In presenting my theory I undertook to perform an expressive act that cannot be undertaken through use of sentence (L) alone.

Someone might reply to this as follows: It's true that (L) self-refers, while (B) does not. And no one is denying this important difference. But it is the only difference between (B) and (L). And-as you yourself acknowledge-mere self-reference does not disqualify something from being true.

To this I reply that self-reference is not the only difference between (L) and (B), though perhaps it is the only grammatical difference. The more fundamental difference lies in the speech acts as such, and not in their grammatical manifestations, although the grammatical manifestations in this instance point the way to the other, more fundamental difference. The purpose of $(\mathrm{L})$ is to say of something (namely of itself) that it is not a correct description. The purpose of (B) is to say of something (namely of $(L)$ ) that it is not a correct description. True: they are trying to make the same point-which is (in a manner of speaking) to say the same thing. Whether they succeed, however, is not a matter that can be settled as a point of grammar or logic. It is entirely a metaphysical affair. Whether the purpose of stating (B) can be achieved utilizing (B) is a different matter from whether the purpose of stating $(L)$ can be achieved through utilizing (L). As I have said, one cannot achieve any expressive act utilizing (L). But it does not follow from this that one cannot achieve an expressive act utilizing (B). As it happens, the purpose of (B) can be achieved: the present essay, give or take, is that achievement.

And this brings us naturally to a novel treatment of the empirical Liars to which Kripke draws attention ${ }^{26}$ So, for example, Nixon asserts "Everything Dean says about Watergate is false," whilst Dean asserts "All of Nixon's utterances about Watergate are false." According to the account unfolding before us, these assertions (taken together) are speech acts falling, not under type (L), but under type (B). They are, but only accidentally, such as to fail, despite making efforts that would ordinarily succeed in drawing attention to truth-bearing entities. And so, despite the fact that we understand each assertion plainly, neither gets to direct attention to a truth-bearer. We understand each assertion as an effort at directing attention to a truth-bearer-in fact, that is what we

\footnotetext{
${ }^{26}$ "Outline of a Theory of Truth," op. cit. J. L. Cohen ("Can the Logic of Indirect Discourse be Formalised?" Fournal of Symbolic Logic 22 (1957), 225-232) takes another engaging example, discussed by A. N. Prior, op. cit: The local paper reports that the policeman has testified that nothing the prisoner says is true, whilst the prisoner has testified that something the policeman says is true. Prior's analysis of this case leads to the conclusion that, if we can be sure that neither policeman nor prisoner says anything else, we shall be obliged to reject the newspaper report on their testimony!
} 
understand when we understand them. And there is no failure of reference in either of Dean's or Nixon's acts of speech. They refer to each other, and no mistake. So we have a clear grasp of the speech act involved in each such statement, as a speech act. But this does not imply that a truth-bearer, or anything else for that matter, has been directed attention to by each speech act taken as a whole. Whether such a truth-bearer exists or not, is, as Kripke was right to point out, an empirical matter.

Let's return once again to the bare structures of $(\mathrm{L})$ and $(\mathrm{B})$. You might ask how one could achieve some end with some utterance $U$, while no such thing can be achieved through replacement of equals-for-equals in U. Two important philosophical points follow. First, the maxim that one can replace equals for equals salva veritate is not true of speech acts. And this makes one suspicious that it holds of any entities, for the following reason, which is now the second of my two important philosophical points. A truth-bearer-the metaphysical entity - cannot simply be a predicate linked or applied to a subject. (Thus illumination of a truth-bearer cannot simply be simultaneous identification of a predicate and a subject.) Otherwise it would be hard to see how something that points toward some unchallenged subject at the same time as directing attention towards some unambiguous predicate could fail to express a truth-bearer-just as I'm saying the Liar does. Furthermore, it would be impossible to say of two distinct acts identifying the same predicate and the same subject-such as (L) and (B) — that one illuminates a truth-bearer and the other does not.

Of course someone might take both these conclusions of mine as reductios of the position now being advanced. Obviously, I view these remarks as philosophical insights rather than as absurdities. I view these as directing us to notice that the act of picking something out is radically and categorically different from the act of making a judgment about it (minimally, judgment also involves aiming), where by contrast the point of view I am opposing holds that making judgments is a special instance of picking out or naming things (in particular, it is the picking out of two things, one as subject and the other as predicate). 27 On my view, the act of referring (on the one hand) and the act of remarking or judging (on the other) belong to different metaphysical categories within the broader category of speech acts. ${ }^{28}$ The view opposing mine utilizes an impov-

\footnotetext{
${ }^{27}$ This was in particular Frege's view, and was taken over and extended by Wittgenstein in that most notorious doctrine of what shows forth but cannot be spoken. (Most illuminating on this subject are Jane Heal, "Wittgenstein," Stanford Encyclopedia of Philosophy, and Peter Geach, "Saying and Showing in Frege and Wittgenstein," Essays in Honor of G. H. von Wright (Amsterdam: North Holland Publishing, 1976), 54-70.) I am claiming that there are no reasons so far illuminated that would cast genuine doubt on the idea that anything can be the content of a speech act. Frege's and Wittgenstein's reasons for being doubtful on the matter begin importantly with the assumption to the effect that a truth-bearer places a subject under a concept. And this, as I'm arguing, is just false.

${ }^{28}$ In phenomenology a distinction is made between categorial objects, and (ordinary) objects of perception that are revealed in manifolds of appearances; see for example, Robert
} 
erished metaphysics, a point that can now be brought out further through the example with which we started: the phone call.

It is a precondition of making a phone connection, in such technological circumstances as we find ourselves, that the receiver at the destination point be on the hook. The "grammar" of the two acts-phoning oneself and phoning someone else-is the same. Still, there is more to making a phone call than this "grammar." Phoning someone else, in this analogy, corresponds grammatically to (B) and phoning oneself to (L). A theory such as that which I oppose can find no difference between them, because its metaphysics is flattenedartificially impoverished. A theory of speech acts, on the other hand, is at no such disadvantage. For it is in a position to handle the success conditions of these acts as matters that go above and beyond their grammar. On my view, the boundaries on what can be said or done using language depend (quite locally, in fact) upon the metaphysical conditions that must be satisfied to achieve the aim of so doing under the circumstances. They are not purely logical or formal conditions that are or can be handled purely in an abstract framework such as is now familiar since Tarski.

And we come finally to the fundamental question of whether there is any hope for a sensible formal semantic theory. Is there anything that meaning, as such, systematically contributes to the content of a speech act, such that this contribution could be independently characterized in isolation from the speech act itself? The moral of our investigations is, I think, clear: a speech act is a kind of performance, in real time, that requires a metaphysical theory, and not simply a purely logical one, for its analysis. This idea helps illuminate, and is a generalization of the fact that the meanings of indexicals and demonstratives is insufficient to fix their referents. The moral now is that this reality is quite general: even in the absence of indexicals and demonstratives, there are further "performance" aspects to utterances and judgments that can prevent a successful evaluation as to truth. No doubt something systematic is contributed by vocabulary, but this something semantic is by itself insufficient to yield evaluations as to truth in every instance. Judgment is fundamentally a performance. And the metaphysics of this performance has something to contribute as well. So, to the extent that the metaphysics of judgment can itself be formalized, the prospects for a formal theory of semantics are good. But formal semantics cannot stand on its own. Furthermore, the theory of truth must itself be, fundamentally, a metaphysical theory. The theory of truth must be fundamentally a theory of judgment.

Sokolowski, Introduction to Phenomenology (New York: Cambridge University Press, 2000). My point in the text reveals the need for a distinction between the categorial act and the purely referential one. 


\section{THE SELF-DEFEATER}

There is, interestingly, another species of problem with parallel themes to our own-an explicitly pragmatic problem, which I will call the Self-Defeater ${ }^{29}$

We are executors of an eccentric's will. She has made a provision, which is read in the presence of all potential beneficiaries, that you-who are not related by blood ties or personal acquaintance to her-are to be offered a choice between goods $A$ and $B$, each of modest but not identical market value, but no symbolic or sentimental value to anyone. She further provides that if you make the/an irrational choice between $\mathrm{A}$ and $\mathrm{B}$, you will receive the balance of her estate-a sum surpassing any you might have imagined possible. And she specifies explicitly that she, like Bertrand Russell before her, upholds the principle that "Reason signifies the choice of the right means to an end you wish to achieve. It has nothing whatever to do with the choice of ends. 30 You are made aware of the terms of the will, and (naturally) are favorably disposed towards receiving title to the estate. Which of A or B will you choose?

You consider choosing A. Suppose it is the irrational choice, on the understanding that to be rational is to choose the best means to a (highly-ranked) self-given end. Then by choosing it you achieve your (ultimate) aim of inheriting the estate-an aim that cannot be achieved except through making an irrational choice. So it is the rational choice after all, by the standard that to be rational is to choose the best means to a self-given end. But if it is the rational choice, then by choosing it you forfeit the estate; hence it is not the rational choice after all. The same goes for $\mathrm{B}$, no matter how you independently estimate the desirability of $B$ in relation to that of $A$. How can you choose rationally? Perhaps you conclude that no matter what you do you deserve the estate, since anything you do under these circumstances will be irrational. But if this is true, then we might say that anything you do will be rational, since it would precipitate your inheritance.

And the matter is no better from the perspective of those who act for the testator. Suppose you elect option A. Shall we transfer the estate over to you? Suppose $A$ is indeed the irrational choice. By choosing $A$, therefore, you become from our perspective eligible to inherit the estate. Since inheriting is-as we know it to be-your ultimate goal, the choice of $A$ is the rational choice after all. Hence we cannot award you the estate. Suppose on the other hand $\mathrm{A}$ is instead the/an rational choice. By choosing $A$, therefore, you are from our perspective ineligible to inherit the estate. But since inheriting is your ultimate goal in the matter, the choice of $A$ is irrational, and we may proceed with transferring the estate over to you after all. And all of this is true of $B$ as well. So whether you choose $A$ or $B$ we cannot decide whether to proceed with transferring the estate. Hence neither you nor we (acting for the

\footnotetext{
${ }^{29}$ The case is a modification of an example found in Haim Gaifman's "Infinity and SelfApplications, I" Erkenntnis 20 (1983) I3I-I55.

${ }^{\circ} \mathrm{B}$. Russell, Human Society in Ethics and Politics (London: Allen and Unwin), 1954, viii.
} 
testator) can extract ourselves from our dilemma by performing suitable acts of deliberation.

Now I have taken it as a simple truth, in need of no special support, that any aim which is such that any road to its fulfillment involves its nonfulfillment, is simply one which is not capable of fulfillment. (You will recall that I called such an aim self-defeating, and I declared on that basis that the aim to fail at my only aim is self-defeating, hence unachievable.) The Self-Defeater case now before us presents a special instance of an aim-to wit, the aim to make an irrational choice, in order to further a second (quite respectable) aim of attaining a prize-that qualifies under my definition as self-defeating. That aim thus is (on my account) incapable of fulfillment. Notice that a large number of the types of conflict we have been reviewing come together in the Self-Defeater. There is an impossibility of concluding the deliberation process on both "sides": testator's and potential beneficiary's. There is the (logical) difficulty of judging a decision as either rational or irrational, although for all the world it looks to be in the market for being one or the other, since it will inevitably be performed deliberately and with the weight of reasons behind it. And, as I say, there is also the explanation of all these things: directly conflicting or self-defeating aims - in this case both, if we assume that the testator of the will composed it deliberately and precisely as an instrument for bringing it about that you (whom she despised for many years) shall, like Tantalus, have no means of proceeding that puts the prize in your sights also within your reach.

The conflicted aims that figure in this evil benefactress story prevent there being anything truly eligible of being called the better or the more rational thing for you to choose. But surely we should not say-and indeed no one has ventured to say, in spite of this story's unoriginal provenance-that therefore there is a logical disease inherent in the notion of rationality quoted by the deceased, or simply in the notion of betterness of choice, and that this example brings to our attention a need to remove that defect. Surely the story would prove entirely too much if it did. To be sure, one can have such an aim as you are seeking so hopelessly to achieve-fiction of evil benefactress notwithstanding.

But now someone is sure to complain that really the aim you are hoping to achieve is not in reality an aim at all. For if we suppose it is, and if we suppose furthermore that there is such a thing as a rational choice in the matter (or even such a thing as a better or worse choice), then we end up with a flat contradiction (as we did just paragraphs ago). So, unless we are prepared to give up the idea that there is such a thing as a rational choice in the matter, we should just give up the notion that such an aim as you are purporting is really possible. And if we do that, of course we upturn my entire speech act project of founding certain logical facts upon aims. I reply that there is another way out of this alleged difficulty for my account. I say that this example highlights only the simple fact that circumstances and our fellow human beings can conspire together to punish anyone who is capable of engaging such means as are allowed them or are within reach, in the service of their aims. 
That you can have an aim to choose irrationally, in such a circumstance as the Self-Defeater example, is plainly and simply undeniable. In such an instance, your punishment is achieved by a rendering of the notion of a better or more rational choice either indeterminate or simply undecidable, through there being no way of satisfying the preconditions for determination or decidability. There is no contradiction. Your case is just an instance in which the normal processing rules for the concept in question become suspended or inapplicable. This is something the deceased achieves by creating the existence of too many reasons against the eligibility of each choice as better. And this, I say, is further-not lesser-testimony to the power of speech acts.

\section{VARIETIES OF CONFLICT}

Logical conflict is contradiction. It is that which exists amongst truth-bearers that cannot all be true together. So if I embrace the self-contradictory truthbearer: "It's raining, and also it's not raining," I thereby introduce logical conflict into my body of beliefs, since the two halves of this truth-bearer cannot both be true. And if subsequently that corpus cannot maintain logical integrity, because the self-contradictory truth-bearer enables exponential growth in the sum total of logical conflict (if we are allowed to speak as if logical conflict were a substance that can accumulate), we will wish to say that condition stems or flows from the logical conflict within the original contradiction. For the subsequent trouble with my corpus is as logical in origin, as it is logical throughout.

There is a strong current within academic philosophy in the analytic tradition that strives for viewing conflict of every kind as stemming from some form of logical conflict-some contradiction. And so we find the notion of paradox defined (or better, codified) by Quine (for perhaps not originated by him) as a piece of argumentation, involving a chain of apparently impeccable inference steps, in a reasoning process that takes its departure from premises thought to be true, or definitions thought to be unproblematic, and makes a passage to a truth-bearer that is either inconsistent or surprising. Quine, for his part, distinguished three species under the genus paradox ${ }^{31}$ The first of these he called "veridical paradoxes;" they reveal a surprising truth, for example that one can be I2 years old and even so have enjoyed but three true birthdays in one's whole lifetime. The second species he called "falsidical paradoxes;" they expose a falsehood or an error-introducing procedure (if we are not sufficiently vigilant), which previously went unnoticed, such as for example the procedure of dividing by zero, brought to attention by Augustus DeMorgan through the effect of using it to derive a falsehood from a truth. And the third he called "antinomies," thereby marking them as the most philosophically rich. Antinomies, he said, necessitate far-reaching revisions in extensive networks of conceptions and presuppositions. On this view of paradox, therefore-which has come to

31"The Ways of Paradox," in The Ways of Paradox, (Cambridge: Harvard University Press, I966), I-I8. 
be the prevailing view - the most philosophically rich paradoxes stem or result from conflict amongst the abstract entities that figure in logical analysis.

But on Quine's three-part taxonomy, assertion of for example Moore's statement "It's raining, but I don't know it," does not qualify as paradoxical, since what is said thereby is a commonplace truth, and involves nothing at all that is either surprising or contradictory. But surely Moore's puzzle, and others like it (such as "I am dead"), which now all go under the title "pragmatic paradoxes," require philosophical diagnosis, 32 The term speaks of conflict of an entirely familiar sort, amongst the ordinary players of day-to-day life-such as the utterances, aims and actions of ordinary mortals. One aim of this essay has been to sketch in a broad brush a variegated landscape of conflict types that can be entered into by entities of different sorts.

By taking in Moore's statement I do not thereby introduce a contagion of logical conflict into my corpus-as by contrast I do when embracing "It's raining and it's not raining." For it is entirely possible for Moore's statement to be true, as for example when I don't trouble to form a belief on the subject of the weather, or when I unsuspectingly accept an excessively optimistic weather forecast. There is conflict, to be sure, in my accepting a proposition to the effect that I have no knowledge about a certain subject, when I've just revierwed my opinion on that same subject, but this is not logical conflict. It is, instead, conflict between two of my actions, which is such that each impeaches the sincerity of the other 33

So the more fundamental question I am raising here is as follows: Is logical conflict - that is to say, contradiction-more fundamental than pragmatic conflict of the familiar sort amongst the figures of day-to-day life? In other words, if we can identify a logical conflict in combining (for example) Moore's statement together with some principles I may be said to accept through making the statement-such as for example, 'If I accept P, then I accept that I accept P as true'-should we then conclude that all surrounding conflicts, and in particular the pragmatic conflict between my two actions, also flow from the logical conflict, as derivative problems? Is a logical conflict, when found with others, always the source, font or locus of the whole business-so that if we can manage somehow to exorcize the logical conflict, everything else would fall into

${ }^{32}$ Philosophical audiences were introduced to pragmatic conflict, under the name of "pragmatic paradox," by D. J. O’Connor, “The Pragmatic Paradoxes," Mind 57 (I948), 358-359, since which time there have been numerous proposals to identify hidden logical conflict as the source of their troubles.

${ }^{33}$ The conflict between my two actions, for example in the Moore's statement instance, does not consist in my being unable to make an announcement, which would give its recipients to believe that I have carried out the conflicting actions in question: I can make such an announcement, and no mistake. For all that, the actions in question are in conflict, and (as we will see) an announcement which gives us to believe I have carried both out successfully is a self-impeachment. My full diagnosis of Moore's statement appears in "Paradox and its Undoing: A Speech Act Manifesto," in John Woods and Bryson Brown, eds., Logical Consequence: Rival Approaches, (Paris: Hermes Science Publications, 200I), 297-308. 
place? Not surprisingly perhaps, the customary assumption amongst philosophers in the tradition of analysis is Yes: for amongst them it is customary to view logical conflict as the root of all evil, wherever it happens to erupt. I am challenging this conventional wisdom, through analysis of the most important case of alleged antinomy: the Liar.

Robert Koons argues that practical impossibilities such as the ones I have brought to attention flow from impossibilities of a logical nature 34 Thus, by implication, that the logical conflicts involved are more fundamental or primary, and that the practical difficulties are derivative in nature. Koons's assumption (although, admittedly, he is not explicit on the subject) seems to be that practical matters have got to be less fundamental because they rest on beliefs. So difficulties for belief formation will give rise to practical problems. But more importantly, difficulties for belief formation rest on logical difficulties. Thus upon showing that there is a logical conflict involved in achieving certain combinations of beliefs in a justifiable way, he immediately infers from this that all the pragmatic impossibilities stem from this logical conflict. On Koons's picture-which I dare say is near-universal-beliefs rest on a bedrock of logical fundamentals only. And the phenomenon of belief formation, together with semantic fundamentals, form the foundation on which rest all aims and actions.

I have argued that achievement of many beliefs-specifically the commonperspectival sort-rests on a certain type of practical negotiation. And so common-perspectival beliefs cannot be attained (in the fundamental sense of achieving a state of equilibrium with all one's evidence and other beliefs) unless these negotiations can be carried out. When these negotiations cannot be carried out, there can be no such beliefs. Thus that pragmatic matters can be fundamental-more fundamental than the beliefs on which they rest, but also more fundamental than certain semantic matters, such as whether a certain sentence token is potentially true. The former (the practical impossibilities) will explain the latter (the semantic impossibilities). In fact, I am saying that practical problems can be of such a kind as to prevent utterances from expressing truths. Thus I am turning the customary picture of things on its head. For I am arguing that certain logical phenomena, pertaining to whether certain utterances are true, rest on whether certain aims are achievable. Thus that the phenomena of which utterances carry truth rest firmly and fundamentally on a bed of pragmatic fundamentals. This is a speech act doctrine. And it makes an important difference to how we go about diagnosing the paradoxical and the awkward.

Why bother about diagnosing paradoxes correctly, as long as we take measures to keep logical conflict from erupting? One answer, of course, is that we care to understand why logical conflict erupts, what is the fundamental nature of the problem which gives rise to it in a given case. Another answer is that the

\footnotetext{
${ }^{34}$ Paradoxes of Belief and Strategic Rationality (New York: Cambridge, 1992), 13-23.
} 
very question presupposes that all those conflicts which lead to paradox are philosophically treatable. And this presupposition is-without qualificationincorrect. The dogma of the primacy of the logical rests on an unexamined faith in the power of philosophical remedies.

\section{DIAGNOSIS AND TREATMENT OF PARADOX}

A pragmatic paradox typically involves a single source of information that to all appearances impeaches itself, leaving us not knowing what to make of the whole business. We would like to have a philosophical account of such impeachments, and additionally an all-embracing, scientific taxonomy of the means by which they can be achieved. But self-impeachment is not a special case of inconsistency. If anything, things are just the other way around: inconsistency is a specific means to self-impeachment. Thus the more celebrated paradoxes (the antinomies) are special instances of a larger class of conflict entered into by the ordinary players in day-to-day activities. And it is the lesser-celebrated specimen of paradox - the pragmatic specimen - that is the more representative member of this larger class. This suggests that we cannot improve upon Quine's taxonomy simply by adding more categories alongside Quine's three, at the same level of generality. We've got instead to insert Quine's limited taxonomy into a more embracing one. This idea is suggestive; for might it not be true that some of the celebrated semantic paradoxes admit of remedy-if they do at all-in much the same way that pragmatic paradoxes do? If so, there might be fewer antinomies than are currently done the honor of the name. This is precisely what I have undertaken to defend-that the Liar itself is no antinomy.

Critics and other skeptics can be relied upon to reply that I am making too much of the distinction between the pragmatic and the logical. And that while one could perhaps invert (as I am suggesting, in defiance of canon) the order of genus and species, thereby lending support (perversely, as they are sure to say) to the speech acts doctrine whereby the logical is a special case of the practical, one can equally well view the practical as a specimen of the logical, simply by noting that the principles or axioms governing the practical can themselves be written down in a system or language whose rules of inference are well articulated. It will follow, for example, that if a human being cannot jump from earth to moon in one bound, this fact should have an image in an appropriate axiomatic system. And it will follow as well that if I cannot jump from here to the moon in one bound and remain human, this should seem paradoxical (or even peculiar) no more than it should seem paradoxical that I cannot marry three different individuals and remain monogamous. And it will follow from all this that something is a practical paradox only if we could present a pair of compelling arguments for contradictory premises to the effect that someone both can and cannot do something. And so it will make no difference whatever whether we think of the paradoxical thing as logical in character or practical in 
character.

This counter to my argument amounts more or less to an expression of the idea that the principles of a practice-for example the practice of asserting, or promising, or advising, or commanding, or seeking fulfillment in some other way to a form of speech that follows - can be formulated as a set of axioms, and these put in place within an inference engine together with the contents of the speeches themselves. And if something is paradoxical, it should follow that the inference engines can achieve a deduction of a contradiction from that something 35 (Of course, this analysis does not itself distinguish between the unabashedly and obviously contradictory—such as ' $\mathrm{P}$ and not-P'—and the paradoxical, since contradictions arising from a deep kind of logical conflict are deducible too from the superficial variety of which the (canonically empty) ' $P$ and not- $P$ ' is a specimen. But presumably we will be able, independently, to produce the compelling arguments on each side of the relevant contradictions for those items that are indeed paradoxical.)

Now I reply that, to the contrary, it does indeed make a good deal of difference whether we view the problem at the root of a paradox as practical, on the one hand, or logical, on the other. For if we could simply choose to view it all as a matter of logic, as my opponents' reply above suggests, or equivalently as a matter of problematic concepts or semantics, then we would be in a position to see ourselves as capable of choosing a different set of concepts or axioms or inference engines or semantic devices, if it turns out that contradiction brings on pain, panic or some other form of distress. As if the practices of asserting or promising or commanding or advising or what-have-you, could be different from what they are, or extinguishable when pressure of a certain and sufficient sort is brought to bear. And this assumption may be false.

Now you might say that it does not follow, that a treatment of our practices via a system of axioms, automatically presupposes that there is something optional about the practices. One can handle something as a problem of logic-a problem of figuring out what's wrong with a certain system of axioms, and thereby endorse the doctrine that logical conflict is the most fundamentalwithout committing the presupposition that, therefore, there is always the option to revise our concepts or practices, so as to remove the offense housed within that system of axioms. One could, for example, view the problems revealed within a certain axiom system, as illuminating important metaphysical facts, which are furthermore not subject to remedy. Couldn't one? I say in response that the most such an approach could guarantee, is a display of the fact that something is amiss with a system so displayed — which we might very well know already — but does not furnish enough latitude for diagnosing all the potential problems with such a system. So that such an approach would only be paying lip service to the notion that axioms and concepts are sometimes

\footnotetext{
${ }^{35}$ This, essentially, is the decision taken by Daniel Bonevac in "Paradoxes of Fulfillment," Fournal of Philosophical Logic, 19 (1990) 229-252.
} 
immune to revision. Here is why.

The choice of representing the practices of asserting, promising, commanding, and so on, within a system of axioms, puts them-these practices-in the same category as definitions of concepts or terms. And this way of handling them makes no distinction whatever between, on the one hand, what is up to us to accept and hence practically optional, and what is practically or in some other way mandatory. In other words, it does not require making a distinction between axioms asserting their content with a force of necessity, on the one hand, and axioms that assert their content without any such force, on the other hand. (It does not require making a distinction between, for example, the axiom: 'Asserting $X$ is accompanied, as a matter of practical necessity, by an aim of the sort A,' on the one hand, and the axiom: 'Asserting $X$ is accompanied by an aim of the sort A,' on the other.) Now I claim that this failure to require a distinction, itself amounts to a methodological assumption, and an enormously substantive one at that. The reason it amounts to an assumption is that it fails to require dividing between the revisable and the nonrevisable explicitly, where doing so is potentially a means to throwing light on what may be at stake in the ensuing contradiction. As if making that distinction is never material to diagnosing the problem from which stems the contradiction. In other words, the methodology obscures the relationship between the axioms and the inference engines: do the inference engines license merely logical consequences, or do they license inferences of a more metaphysical nature? And this obscuring amounts to a failure to distinguish between the logical dimension in philosophical analysis, as such, which is materially responsible for the contradiction (i.e. which licenses the deduction), and the formal dimension in philosophical analysis, as the genus under which fall all matters logical, which explains why the deduction is licensed. The methodology thus presupposes that all formal matters are logical matters, and this is arguably false. ${ }^{36}$ Thereby this methodology masks over the distinction between revisable and nonrevisable. At the very least, the assumption to the effect that the distinction between revisable and nonrevisable need not be made, at the particular stage of analysis undertaken, should not itself be buried like an ostrich's head in methodology. An assumption to the effect that practices are subject to some (unspecified) form of renewal, even if the possibility of renewal is merely "logical", should in any case be clearly set forward as an assumption. And the question whether to view the logical or something else as most fundamental, is indeed a question of fundamentals, and cannot be (as such) a non-doctrinal matter. So we cannot just bury the issue, and proceed as if it doesn't matter how to approach the relation between the logical and other matters. This should be subjected to debate and analysis, and not to fiat. For if it should turn out that we cannot for whatever

\footnotetext{
${ }^{36}$ This distinction is most forcefully made by Husserl and his expositors. See for example Barry Smith and Kevin Mulligan, "Framework for Formal Ontology," Topoi 2 (1983), 73-85, and Barry Smith and David Murray, "Logic, Form and Matter," Proceedings of the Aristotelian Society LV (I98I) 47-63. See also B. Smith, "The Substance of Brentano's Ontology," Topoi 6 (I987), 39-49.
} 
reasons, simply and matter-of-factly reverse our practices and institute something else instead, it will follow that the origins of practical paradox are not logical at all, and are instead founded upon metaphysical facts of another sort. The doctrine of speech acts prevents us falling prey to these errors. 
The Australasian fournal of Logic (ISSN I448-5052) disseminates articles that significantly advance the study of logic, in its mathematical, philosophical or computational guises. The scope of the journal includes all areas of logic, both pure and applied to topics in philosophy, mathematics, computation, linguistics and the other sciences.

Articles appearing in the journal have been carefully and critically refereed under the responsibility of members of the Editorial Board. Only papers judged to be both significant and excellent are accepted for publication.

The journal is freely available at the journal website at

$$
\text { http://www.philosophy.unimelb.edu.au/ajl/ }
$$

All issues of the journal are archived electronically at the journal website.

SuBSCRIPTIONS Individuals may subscribe to the journal by sending an email, including a full name, an institutional affiliation and an email address to the managing editor at ajl-editors@unimelb.edu.au Subscribers will receive email abstracts of accepted papers to an address of their choice. For institutional subscription, please email the managing editor at ajl-editors@unimelb.edu.au.

Complete published papers may be downloaded at the journal's website at http: //www.philosophy.unimelb.edu.au/ajl/ The journal currently publishes in pdf format.

Submission The journal accepts submissions of papers electronically. To submit an article for publication, send the $\mathrm{LT}_{\mathrm{E}} \mathrm{X}$ source of a submission to a member of the editorial board. For a current list of the editorial board, consult the website.

The copyright of each article remains with the author or authors of that article. 